\title{
Rare Earth Oxide Coatings to Decrease High Temperature Degradation of Chromia Forming Alloys
}

\author{
Stela Maria de Carvalho Fernandes, Lalgudi Venkataraman Ramanathan* \\ Instituto de Pesquisas Energéticas e Nucleares \\ Travessa R-400, Cidade Universitária \\ O5422-970 São Paulo - SP, Brazil
}

Received: September 2, 2002; Revised: September 4, 2002

\begin{abstract}
The addition of small quantities of reactive elements such as rare earths (RE) to chromia or alumina forming alloys improves the high temperature oxidation resistance. Traditionally, these elements are alloying additions or are added as oxides to form a dispersion. The alloys can also be coated with RE oxides. Several methods can be used to coat alloy substrates with RE oxides and the sol-gel process is considered to be quite efficient, as it generates the very small oxide particles. This paper presents the influence of surface coatings of $\mathrm{Ce}, \mathrm{La}, \mathrm{Pr}$, and $\mathrm{Y}$ oxide gels on the oxidation behavior of an Fe-20Cr alloy at $1000{ }^{\circ} \mathrm{C}$. The morphology of the rare earth (RE) oxide coatings varied with the nature of RE. The oxidation rate of RE oxide coated Fe-20Cr was significantly less than that of the uncoated alloy. The extent of influence the RE oxide coating exercised on the oxidation rate decreased in the following order: $\mathrm{La}, \mathrm{Ce}, \mathrm{Pr}, \mathrm{Y}$. The scale formed in the presence of RE oxide was very thin, fine grained and adherent chromia. A direct correlation between rare earth ion radius and the extent of influence on chromia growth rate at $1000{ }^{\circ} \mathrm{C}$ was observed.
\end{abstract}

Keywords: oxidation, rare earth, coatings

\section{Introduction}

Metallic materials for use at high temperatures are usually iron, nickel or cobalt based alloys. The surface oxide formed on these metals in oxidizing environments are not sufficiently protective above $550{ }^{\circ} \mathrm{C}$, and are therefore alloyed with $\mathrm{Cr}$ and $\mathrm{Al}$ to establish more protective oxide scales of chromia or alumina respectively. The scales, in order to be highly protective should be: (a) stoichiometric; (b) free of pores, cracks or other defects; (c) free of stress at operating temperaturee and (d) resistant to spallation ${ }^{1}$. In practice, it is almost impossible to form such ideal scales. However, the addition of rare earth (RE) elements such as yttrium or cerium to these alloys, has been shown to improve the properties of chromia and alumina scales. In the case of chromia scales, REs have been shown to: (a) improve scale adherence, especially under thermal cycling conditions; (b) reduce the scale growth rate constant (for steady state growth) by a factor of up to 10 or more; (c) reduce the chromium content necessary in the alloy to form a continuous chromia scale, from $20-35 \%$ to $10-13 \% \mathrm{Cr}$; (d) change the scale growth mechanism, from scale growth at the oxide/gas interface to scale growth at the metal/oxide interface and (e) reduce the grain size of the scale ${ }^{2}$. Several mechanisms have been proposed to account for these beneficial effects of adding the reactive elements, and some of these have been verified for specific alloys under specific conditions ${ }^{3,4}$.

The RE elements can be added to heat resistant alloys either in elemental form or as oxide dispersions ${ }^{5,6}$. The REs can also be introduced into the surface by ion implantation techniques or applied superficially by a variety of techniques $^{7-14}$. Application of RE oxides to metallic surfaces can be done by immersion in aqueous RE nitrate solutions followed by thermal decomposition of the solid nitrate to oxide. Other precursors for RE oxide coatings can be a molten nitrate salt, oxide slurries, or colloidal dispersions of hydrous oxide (sol). The sol gel technique is known to generate the smallest oxide particles ${ }^{5}$. Essentially this technique is based on the use of sols, which consist of a stable dispersion in a liquid of colloidal units of hydrous oxides or hy-

*e-mail: lalgudi@net.ipen.br

Presented at the International Symposium on High Temperature Corrosion in Energy Related Systems, Angra dos Reis - RJ, September 2002. 
droxides ranging in size between $20 \AA$ and $1 \mu \mathrm{m}$. Metallic substrates are coated with the sol using suitable methods, such as dipping, spin coating or electrophoresis. On drying (removing water from the colloidal units), the sol is transformed into a gel ${ }^{5}$.

The use of RE oxide coatings has the advantage of not affecting adversely the mechanical properties of the alloy and it has also the potential of being used on surfaces of metallic components exposed to high temperature oxidizing environments. This paper presents the influence of surface coatings of $\mathrm{La}_{2} \mathrm{O}_{3}, \mathrm{Pr}_{2} \mathrm{O}_{3} \mathrm{Y}_{2} \mathrm{O}_{3}$ and $\mathrm{CeO}_{2}$ applied by the sol-gel technique on the oxidation behavior of an $\mathrm{Fe}-20 \mathrm{Cr}$ alloy at $1000{ }^{\circ} \mathrm{C}$. The mechanism by which the rare earth oxides affect the oxidation behavior is also presented.

\section{Methods and materials}

Sols of $\mathrm{Y}_{2} \mathrm{O}_{3}, \mathrm{La}_{2} \mathrm{O}_{3}, \mathrm{CeO}_{2}$, and $\operatorname{Pr}_{2} \mathrm{O}_{3}$ were prepared as aqueous dispersions of the respective oxides in nitric acid and a non-ionic surfactant. The solutions were heated to $80{ }^{\circ} \mathrm{C}$ under constant agitation for $1 \mathrm{~h}$ and the sol formed as sediment. Fe-20Cr specimens $1.0 \mathrm{~cm} \times 1.0 \mathrm{~cm} \times 0.5 \mathrm{~cm}$ were ground to 400 mesh, rinsed and dried. The RE oxide sols were sprayed onto specimens that were then heated to $150{ }^{\circ} \mathrm{C}$ to form a surface layer of RE oxide gel. The specimens were subsequently oxidized at $1000{ }^{\circ} \mathrm{C}$ for $40 \mathrm{~h}$.

Scanning electron microscopic examination of the specimen surfaces and cross-sections was carried out, both after coating with the RE oxide and after oxidation. Analysis of the surface scales using energy dispersive spectroscopy and $\mathrm{x}$-ray diffraction was also carried out.

\section{Results and discussion}

The micrographs of the Fe-20Cr alloy specimens covered with the different RE oxides and oxidized for $40 \mathrm{~h}$ at $1000{ }^{\circ} \mathrm{C}$ are shown in Fig. 1. The $\operatorname{Pr}_{2} \mathrm{O}_{3}, \mathrm{La}_{2} \mathrm{O}_{3}$ and $\mathrm{CeO}_{2}$ gels are uniformly distributed, where as that of $\mathrm{Y}_{2} \mathrm{O}_{3}$ is not. The morphology of the gels varied with the nature of the $\mathrm{RE}$ oxide. While the $\mathrm{CeO}_{2}$ gel consists of elongated crystals, those of the $\operatorname{Pr}_{2} \mathrm{O}_{3}$ gel consisted of finely linked crystals. Similar observations with respect to morphological variations have been reported by other authors, although not for Pr oxide ${ }^{10}$.

Isothermal oxidation measurements revealed weight increases that corresponds to chromia formation. The $\operatorname{Pr}_{2} \mathrm{O}_{3}$ and $\mathrm{La}_{2} \mathrm{O}_{3}$ on the oxidized specimens were still quite adherent and uniformly distributed unlike $\mathrm{CeO}_{2}$ and $\mathrm{Y}_{2} \mathrm{O}_{3}$. Chromium oxide in the form of $\mathrm{Cr}_{2} \mathrm{O}_{3}$ (as detected by XRD analysis) was found in the regions where $\mathrm{CeO}_{2}$ and $\mathrm{Y}_{2} \mathrm{O}_{3}$ had spalled off.

The micrographs of specimen cross-sections after oxidation at $1000^{\circ} \mathrm{C}$ are shown in Fig. 2. This figure also shows chemical composition profiles. The chemical composition across the alloy/scale/coating interfaces was determined by EDS. The elemental percentages and the distances (depths) are relative values, to enable comparisons across the interfaces to be made. Region 1 in Fig. 2a shows a high Pr content and region 2 in the same figure reveals a high $\mathrm{Cr}$ content. X-ray diffraction analysis showed the latter regions consist of chromia. The overall thickness of the chromia was 2.5 to $5 \mu \mathrm{m}$. The composition profile across the interfaces on the specimen coated with $\mathrm{La}_{2} \mathrm{O}_{3}$ was similar to that in Fig. 2a for $\mathrm{Pr}_{2} \mathrm{O}_{3}$ and the specimens coated with $\mathrm{CeO}_{2}$ is shown in Fig. 2b. The average chromia thickness varied with the nature of RE oxide. Fig. 2c shows the cross-sectional micrograph and composition profile for an uncoated $\mathrm{Fe}-20 \mathrm{Cr}$ specimen oxidized at $1000^{\circ} \mathrm{C}$ for $40 \mathrm{~h}$.

\section{General discussion}

Comparison of the element profiles in Fig. 2 reveals that the oxide formed at $1000{ }^{\circ} \mathrm{C}$ under all the rare earth oxide coatings is chromia. The porous nature of this RE oxide permits oxygen from the air to react with the chromium to form chromia. The RE oxides are also considered to act as preferential nucleation sites for chromia formation ${ }^{15}$. Entrapment of RE oxide within the chromia layer has been observed. The marked reductions in the rate and extent of oxidation of specimens coated with RE oxides can be attributed to the presence of the RE oxides within the growing chromia. Growth of chromia in the $\mathrm{RE}$ free $\mathrm{Fe}-\mathrm{Cr}$ alloys is cation driven, and the oxide scale growth takes place at the oxide/oxygen interface, owing mainly to the higher mobility of chromium ions than oxygen ions. The reduced chromia growth rate in the presence of REs is directly attributable to reduction in chromium ion mobility. Since grain boundaries are the preferred paths for ion transport in compact scales, the reduced chromia growth rate in the presence of REs is a result of the reduction in chromium ion movement along grain boundaries caused by the presence of barriers, in other words by the presence of RE ions ${ }^{3,16}$. Proof of this has been observed and similar observations were presented by Papaiacovou and Hussey for scale growth on ceria coated $\mathrm{Fe}-\mathrm{Cr}$ alloys ${ }^{12}$.

The $\mathrm{RE}$ ions are significantly larger than $\mathrm{Fe}$ or $\mathrm{Cr}$ ions $\left(\mathrm{R}_{\mathrm{Fe}}=0,63\right.$ and $\left.\mathrm{R}_{\mathrm{Cr}}=0,64\right)$, and the ionic radii of the RE elements used in this investigation, as a function of the chro-

Table 1. Ratio of ionic radii of RE element and chromium.

\begin{tabular}{cc}
\hline Rare earth element & $\mathrm{R}_{\mathrm{RE}} / \mathrm{R}_{\mathrm{Cr}}$ \\
\hline Lanthanum & 1.64 \\
Cerium & 1.60 \\
Praseodymium & 1.57 \\
Yttrium & 1.39 \\
\hline
\end{tabular}


mium ion radius are shown in Table 1 . The extent to which these RE elements affect oxidation rates is in general proportional to their ionic radii. The observations made in this investigation lend further proof to data presented else- where ${ }^{17}$. The larger the RE ion, the greater is its influence on chromia growth rate. Variations in the extent of influence of RE on chromia growth, extracted from published papers, are shown in Table $2^{18-20}$. It can be seen that the

Table 2. Listing of RE elements in order of increasing influence on oxidation of chromia forming alloys. Data extracted from references mentioned. $\mathrm{r}_{\mathrm{RE}} / \mathrm{r}_{\mathrm{Cr}}$ - ratio of ionic radii of $\mathrm{RE}$ element and chromium.

\begin{tabular}{|c|c|c|c|c|c|c|c|c|}
\hline \multicolumn{3}{|c|}{ Extent of influence } & \multicolumn{6}{|c|}{ References } \\
\hline & \multicolumn{2}{|c|}{5} & \multicolumn{2}{|c|}{18} & \multicolumn{2}{|c|}{19} & \multicolumn{2}{|c|}{20} \\
\hline Low & $\mathrm{RE}$ & $\mathrm{r}_{\mathrm{RE}} / \mathrm{r}_{\mathrm{Cr}}$ & $\mathrm{RE}$ & $\mathrm{r}_{\mathrm{RE}} / \mathrm{r}_{\mathrm{C}}$ & $\mathrm{RE}$ & $\mathrm{r}_{\mathrm{RE}} / \mathrm{r}_{\mathrm{Cr}}$ & $\mathrm{RE}$ & $\mathrm{r}_{\mathrm{RE}} / \mathrm{r}_{\mathrm{Cr}}$ \\
\hline$\downarrow$ & $\mathrm{Y}$ & 1.39 & $\mathrm{Gd}$ & 1.46 & Y & 1.39 & $\mathrm{Y}$ & 1.39 \\
\hline$\downarrow$ & $\mathrm{La}$ & 1.64 & $\mathrm{Sm}$ & 1.50 & $\mathrm{La}$ & 1.64 & $\mathrm{Gd}$ & 1.46 \\
\hline$\downarrow$ & & & $\mathrm{Nd}$ & 1.54 & $\mathrm{Ce}$ & 1.60 & $\mathrm{La}$ & 1.64 \\
\hline$\downarrow$ & & & $\mathrm{La}$ & 1.64 & & & & \\
\hline High & & & $\mathrm{Ce}$ & 1.60 & & & & \\
\hline Alloy & \multicolumn{2}{|c|}{$\mathrm{Fe}-20 \mathrm{Cr}$} & \multicolumn{2}{|c|}{ AISI 304} & \multicolumn{2}{|c|}{$\mathrm{Fe}-26 \mathrm{Cr}$} & \multicolumn{2}{|c|}{$\mathrm{Ni}-20 \mathrm{Cr}$} \\
\hline Test temperature & \multicolumn{2}{|c|}{$1000^{\circ} \mathrm{C}$} & \multicolumn{2}{|c|}{900 and $1000^{\circ} \mathrm{C}$} & \multicolumn{2}{|c|}{$900^{\circ} \mathrm{C}$} & \multicolumn{2}{|c|}{$1000^{\circ} \mathrm{C}$} \\
\hline
\end{tabular}
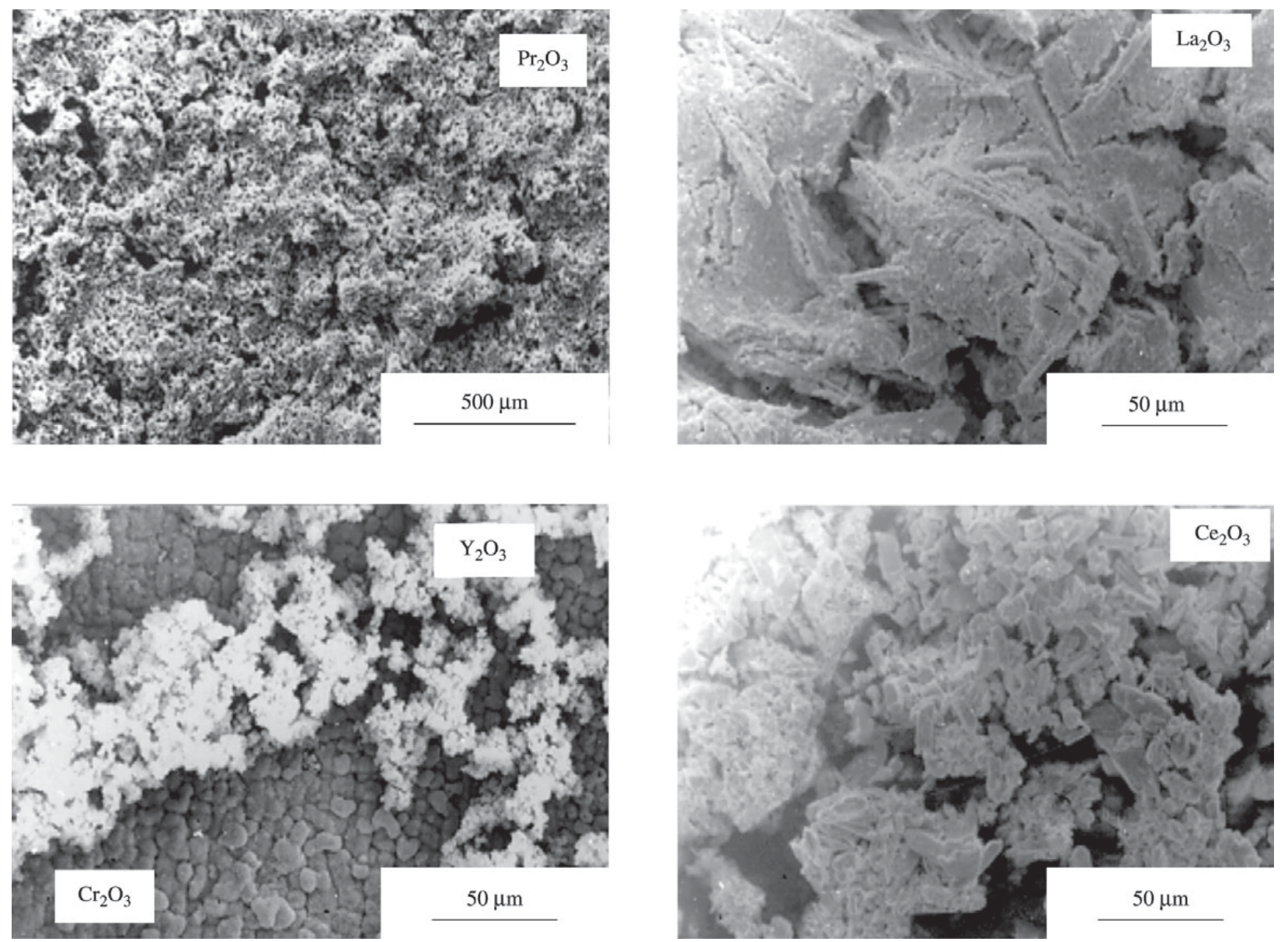

Figure 1. Scanning electron micrographs of Fe-20Cr substrates with given coatings after oxidation at $1000{ }^{\circ} \mathrm{C}$ for $40 \mathrm{~h}$. 

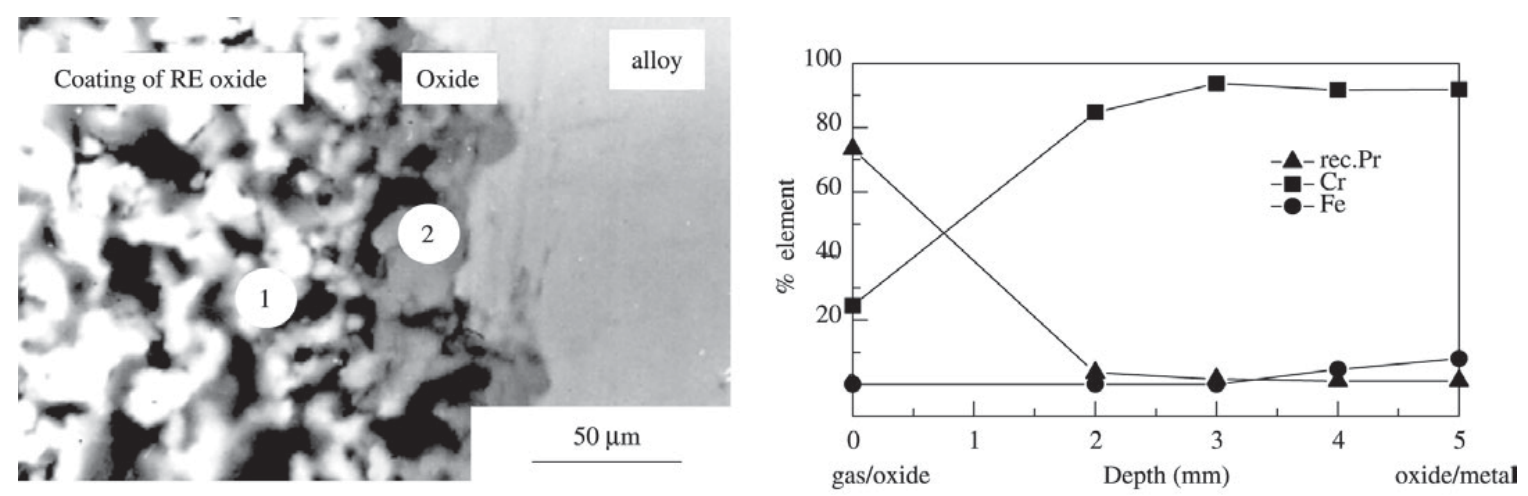

a) $\mathrm{Pr}_{2} \mathrm{O}_{3}$
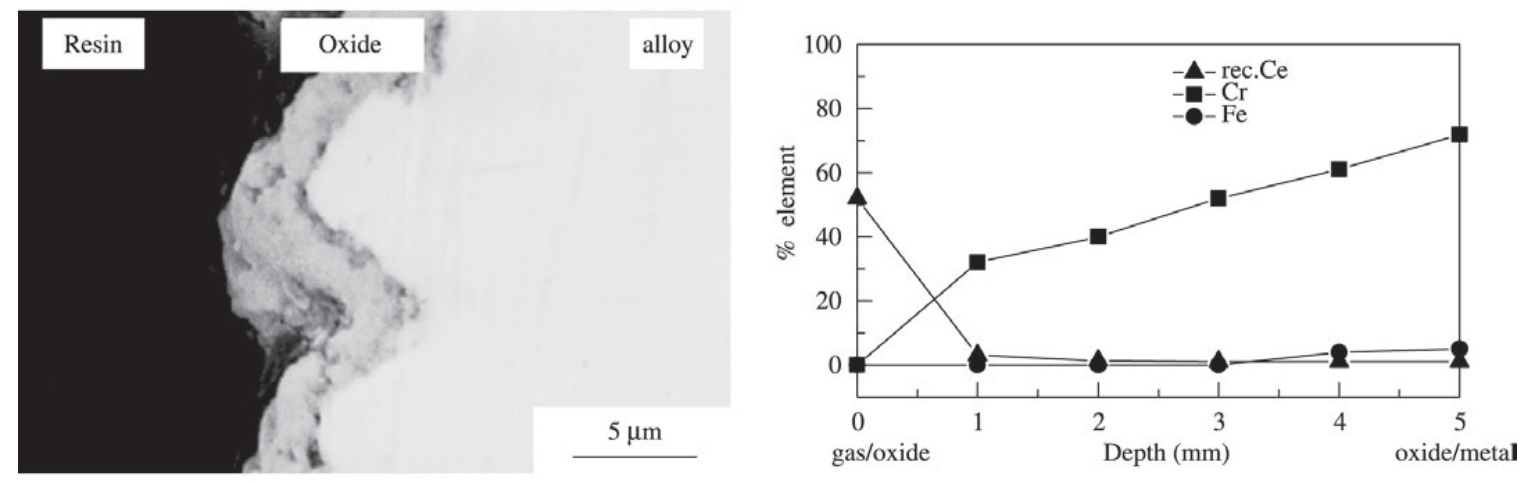

b) $\mathrm{CeO}_{2}$
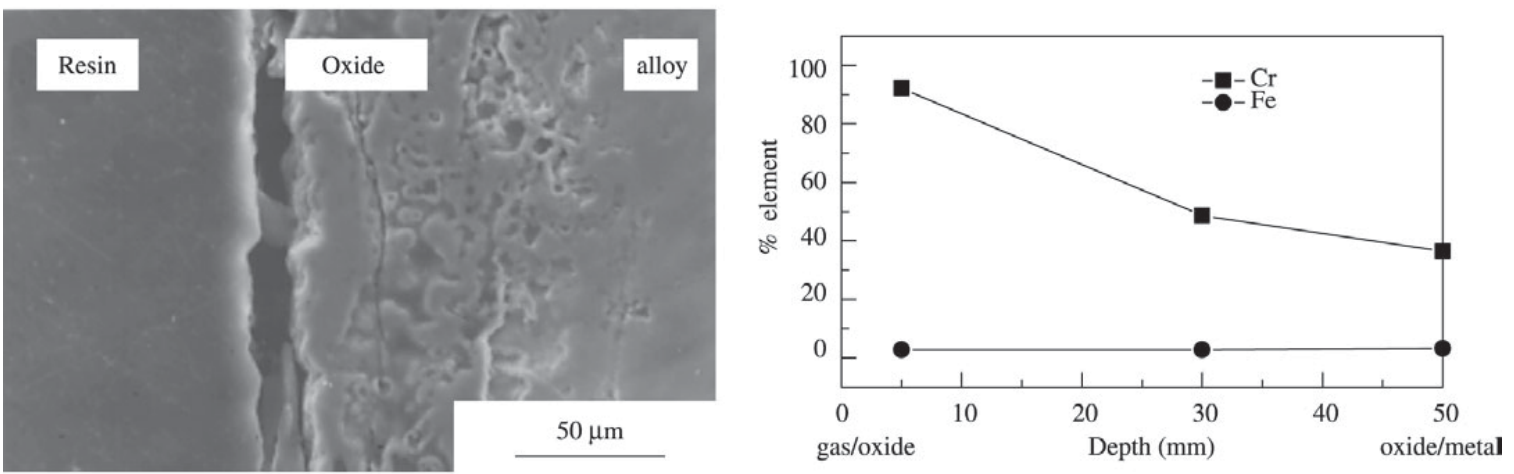

c) uncoated

Figure 2. Cross-sectional scanning electron micrographs and the corresponding element profiles of Fe-20Cr substrates with different coatings after oxidation for $40 \mathrm{~h}$ at $1000{ }^{\circ} \mathrm{C}$.

extent of the influence on chromia growth rate follows the same rationale, substantiating the mechanism by which RE influence chromia scale growth, that is, the presence of RE ions at the oxide grain boundaries effectively block $\mathrm{Cr}$ ion transport, thereby making anion (oxygen ion) diffusion dominant.

\section{Conclusions}

1. The morphology of the RE oxide coatings on $\mathrm{Fe}-20 \mathrm{Cr}$ alloy surfaces varied with the element used. $\operatorname{Pr}_{2} \mathrm{O}_{3}$, $\mathrm{La}_{2} \mathrm{O}_{3}$ and $\mathrm{CeO}_{2}$ were small grained, more uniformly distributed and significantly more adherent than $\mathrm{Y}_{2} \mathrm{O}_{3}$. 2. The oxidation rate of RE oxide coated Fe-20Cr alloy 
was significantly lower than that of the uncoated alloy at $1000{ }^{\circ} \mathrm{C}$. In decreasing order of influence on oxidation rate, the RE elements studied here were La, $\mathrm{Ce}, \mathrm{Pr}$ and $\mathrm{Y}$.

3. $\operatorname{Pr}_{2} \mathrm{O}_{3}, \mathrm{La}_{2} \mathrm{O}_{3}$ and $\mathrm{CeO}_{2}$ were more adherent to the alloy surface even after extended periods of oxidation.

4. Composition profiles across RE oxide/scale/alloy interfaces revealed thinner chromia scales on RE oxide coated than on uncoated specimens.

5. Further evidence of the mechanism of chromia scale growth in $\mathrm{RE}$ containing $\mathrm{Fe}-\mathrm{Cr}$ alloys has been presented. The mechanism involves predominant oxygen ion diffusion (the large RE ions block chromium ion diffusion along grain boundaries) and consequently the chromia scales on RE oxide coated specimens are considerably thinner.

6. Direct correlation between RE ion radius and the extent of influence on chromia growth at $1000{ }^{\circ} \mathrm{C}$ has been observed.

\section{References}

1. Stott, F.H. Mat. Sci. and Tech., v. 5, p. 734, 1989.

2. Stringer, J. Mat. Sci. and Eng., A120, p. 129, 1989.

3. Przybylski, K.; Garratt-Reed, A.J.; Yurek, G.J. J.Electrochem. Soc., v. 135, n. 2, p. 509, 1988.

4. Funkenbusch, R.W.; Smegill, J.G.; Bornstein, N.S. Metall. Trans., 16A, p. 1164, 1985.

5. Nagai, H. Mat. Sci. Forum, v. 43, p. 75, 1989.

6. Rhys-Jones, T.N.; Grabke, H.J. Mat. Sci and Tech., v. 5, n. 4, p. 446, 1988.

7. Antill, J.E.; Bennet, M.J.; Bernsley, R.F.A.; Fern, F.H.; Goode, P.D.; Myatt, B.L.; Furner, J.F.; Warburton, J.W.
Corros. Sci., v. 16, p. 729, 1976.

8. Landkof, M.; Levy, A.V.; Boone, D.H.; Gray, R.; Yanif, E. Corrosion, v. 41, p. 344, 1985.

9. Saito, Y.; Maruyama, T. Mat. Sci. and Eng., v. 87, p. 275, 1987.

10. Hou, P.Y.; Stringer, J. Mat. Sci and Eng., v. 87, p. 295, 1987.

11. Fransen, T.; de Jough, M.A.; Perik, M.M.A.; Gellings, P.J. "The sulfidation of high alloy steels at various sulfur partial pressures. The role of mechanical pre-treatments and the influence of superficially applied cerium (IV) oxide", ( Paper presented at the $9^{\text {th }}$ Int. Cong. On Metallic Corrosion, Canada, p. 311, 1984.

12. Papaiacovou, P.; Hussey, R.J. Corros. Sci., v. 30, n. 4/5, p. $451,1990$.

13. Bennet, M.J. J.Vac. Sci. and Technol., B2, v. 4, p. 800, 1984.

14. Ramanathan, L.V. Corros. Sci., v. 35, p. 871, 1993.

15. Moon, D.P.; Bennet, M.J. UKAEA Rep. AERE-R 12757, 1987.

16. McLean, D. Grain Boundaries in Metals, Oxford University Press, London, 1957.

17. Fernandes, S.M.C.; Ramanathan, L.V. Surf. Engg., v. 16, p. 4, v. 327, 2000.

18. Ramanathan, L.V. "Oxidation behavior of rare earth oxide covered stainless steels", Proc. $9^{\text {th }}$ Brazilian Conference on Materials Science and Engineering, v. 712, 1990.

19. Hussey, R.J.; Graham, M.J. Oxidation of Metals, v. 45, n. 3, p. 349, 1996.

20. Nagai, H.; Takebayashi, Y.; Mitani, H. Metall. Trans. A, v. 12 , n. $435,1981$. 